Revista Iberoamericana. Vol. LXII, Núms. 176-177, Julio-Diciembre 1996; 837-844

\title{
UNA HETEROGENEIDAD NO DIALÉCTICA: SUJETO Y DISCURSO MIGRANTES EN EL PERÚ MODERNO
}

\author{
POR \\ Antonio CoRnejo-Polar \\ University of California at Berkeley \\ Universidad Nacional Mayor de San Marcos
}

Sin duda la migración del campo a la ciudad es el hecho de más incisiva y abarcadora trascendencia en la historia moderna del área andina. Países que hace no muchas décadas eran masivamente campesinos, hoy tienen una población urbana mayoritaria y en constante crecimiento. Para el caso del Perú baste recordar que en cincuenta años la población citadina subió del 35.4\% al 69.9\% (Conapo, 1989, 5), transformándose así, drásticamente, el carácter mismo de la nación. Naturalmente el crecimiento de las ciudades tiene varias razones -y múltiples correlaciones(Quijano, 1977, 1980)_pero ningunatan decisiva e impactante como la migración rural.

De la profundidad de las transformaciones urbanas queda - entre otros muchos- el testimonio del narrador autobiográfico de La tía Julia y el escribidor. Es un fragmento en el que relata su asombro al comprobar lo mucho que ha cambiado Lima durante los diez años que ha estado ausente:

\begin{abstract}
Al salir de la Biblioteca Nacional a eso de mediodía, bajaba a pie por la avenida Abancay, que comenzaba a convertirse en un enorme mercado de vendedores ambulantes. En sus veredas, una apretada muchedumbre de hombres y mujeres, muchos de ellos con ponchos y polleras serranas, vendía, sobre mantas extendidas en el suelo, sobre periódicos o en quioscos improvisados con cajas, latas y toldos, todas las baratijas imaginables, desde alfileres y horquillas hastavestidos y ternos y, por supuesto, toda clase de comidas preparadas en el sitio, en pequeños braseros. Era uno de los lugares de Lima que más había cambiado, esa avenida Abancay, ahora atestada y andina en la que no era raro, entre el fortísimo olor a fritura y condimentos, oír hablar quechua (Vargas Llosa, 1973, 432).
\end{abstract}

Aunque harto obvio, no está demás subrayar el muy significativo contrapunto que se establece entre el santuario del saber oficial, la Biblioteca, que con el conocimiento letrado que acumula debería ordenar y jerarquizar la urbe que la rodea - estoy pensando en términos de la "ciudad letrada" por supuesto (Rama, 1984) - y el indomable desorden plebeyo de las calles que es visto explícita y reiteradamente como andino. La contundencia de esta intromisión desestabiliza al narrador-protagonista, que como intelectual obviamente respeta el valor simbólico de la Biblioteca, y lo sitúa en una posición de ajenidad marginal: no reconoce $s u$ ciudad y en ella - lo dirá poco después - se siente ahora "como un turista" (433). La identidad de la ciudad ha variado de forma sustancial y la relación de pertenencia del 
personaje entra en crisis hasta convertirlo en visitante precario de una ciudad que fue suya y está dejando de serlo. ${ }^{1}$

Ciertamente el texto de Vargas Llosa sugiere otras lecturas posibles, la mayoría de las cuales dejaría en claro ciertas oposiciones explícitas: biblioteca/mercado, por ejemplo, pero también implícitas: el austero silencio de las salas de lectura y el orden escrupuloso de índices y catálogos frente al ruido y al caos de la calle-mercado. Más incisivamente aún: la biblioteca es el espacio de la escritura y su entorno popular-migrante el de la voz, lo que adquiere una dimensión adicional si queda claro - como es obvio- que allá prima el español y aquí "no era raro [...] oír hablar en quechua". De esta manera la cultura letrada aparece agresivamente rodeada por la cultura oral, hasta un punto que también la biblioteca podría asumir, dentro de ese contexto, la condición que se autoasigna el personaje-narrador: un ente extraño, algo extravagante, frente y dentro de una nueva realidad que lo excede y -literalmente- lo descentra.

Permítanme que deje la Biblioteca sólo como punto de referencia y trate de comprender qué sucede en ese espacio "atestado y andino". Es claro, por lo pronto que la masa que ha invadido la avenida Abancay está formada casi íntegramente de migrantes serranos, migrantes que no parecen haber perdido niveles básicos de identidad: lengua, vestido, comida, pero que al mismo tiempo — por supuesto - no pueden dejar de actuar de acuerdo a los masivos e inéditos condicionamentos que la ciudad acumula sobre ellos. Me interesa, pues, el sujeto migrante.

Tengo para mí que a partir de tal sujeto, y de sus discursos y modos de representación, se podría producir una categoría que permita leer amplios e importantes segmentos de la literatura latinoamericana - entendida en el más amplio de sus sentidos- especialmente los que están definidos por su radical heterogeneidad. Como se sabe son varias las categorías que se han usado para dar razón de este enredado corpus. Sin ánimo de sustituirlas, aunque algunas como la de mestizaje parecen haber agotado casi toda su capacidad iluminadora, deseo explorar la pertinencia y la efectividad de esta otra categoría, la de migración y sus derivados, que casi no ha sido empleada en relación a esta problemática (Lauer, 1989). ${ }^{2}$ Sospecho que los contenidos de multiplicidad, inestabilidad y desplazamiento que lleva implícitos, y su referencia inexcusable a una dispersa variedad de espacios socio-culturales que tanto se desparraman cuanto se articulan a través de la propia migración, la hacen especialmente apropiada para el estudio de la intensa heterogeneidad de buena parte de la literatura latinoamericana. Por supuesto: la magnitud del fenómeno migratorio del agro a la urbe que es el que ahora me interesa - también parece avalar, desde un nivel si se quiere empírico, su aptitud hermenéutica. ${ }^{3}$

\footnotetext{
${ }^{1}$ En realidad el texto pone en evidencia la inestabilidad de categorías como centro/periferia o marginalidad al trastocarlas o en cierto modo vaciarlas de sentido: el centro simbolizado por la Biblioteca mantiene en cierta forma su posición pero dentro de una dinámica en la que sin duda ha perdido poder, de la misma manera que el intelectual se marginaliza frente a una realidad que parece ser mucho más poderosa de lo que él representa.

${ }^{2}$ Lauer es tal vez el único que ha tratado el asunto, pero considera sintomática la escasez de textos sobre la migración, lo que no parece ser exacto, aunque luego precisa que se refiere al momento mismo de la migración no a las etapas anteriores o posteriores.

${ }^{3}$ Naturalmente no toda literatura heterogénea responde a fenómenos migratorios. De lo que se trata entonces es de diseñar un modelo que permita ver con más claridad la índole de esta literatura.
} 
Es importante subrayar que desde muy antiguo y hasta hoy existe algo así como una retórica de la migración que pone énfasis en sentimientos de desgarramiento y nostalgia y que normalmente comprende el punto de llegada - la ciudad - como un espacio hostil, aunque de algún modo fascinante o simplemente necesario, a la vez que sitúa en el origen campesino una positividad casi sin fisuras, con frecuencia vinculada a una naturaleza que es señal de plenitud y signo de identidades primordiales. Sintomáticamente esta perspectiva cruza de parte a parte el espesor de los varios discursos que constituyen la literatura peruana y se puede encontrar en canciones quechuas, en formas mestizadas como el yaraví, en cantos criollos de la costay en textos definidamente inscritos en el canon de la literatura culta. No es el momento de acumular citas, pero no sería vano recordar que en el cancionero quechua abundan expresiones de desarraigo que casi siempre tienen que ver con la migración a la ciudad (Montoya, 1987, 423-470); que desde antiguo varias generaciones recuerdan, y hasta hoy, los versos del siguiente yaraví:

Ya me voy a una tierra lejana

a un lugar donde nadie me espera,

donde nadie sepa que yo muera,

donde nadie por mi llorará (Carpio, 1976, 183); ${ }^{4}$

que "Idilio muerto" de Vallejo se construye sobre la oposición entre la plenitud del ayer rural —el de la "andina y dulce Rita"- y la defectividad del presente urbano ("Bizancio") en el que sufre y se enajena el poeta (Vallejo [1918] 1968, 102); o que, por último, "Warma Kuyay" concluye con un texto relativo al momento en que

me arrancaron de mi querencia, para traerme a este bullicio, donde gentes que no quiero, que no comprendo [...] Mientras yo, aquí, vivo amargado y pálido, como un animal de los llanos fríos, llevado a la orilla del mar, sobre los arenales candentes y extraños (Arguedas [1935] 1967, 94).

Sería tentador datar este temple nostalgioso en un tiempo en el que la migración era más una aventura individual que una vasta decisión colectiva. En términos generales sería una interpretación parcialmente adecuada; sin embargo, como ese tono persiste doblemente, como repetición emotiva de textos anteriores y como creación de otros nuevos de índole similar (Florián [1944],1985; Nelson, 1982; Espino, 1990), ${ }^{5}$ prefiero entenderlo como una variante relativizada, por posicional, que puede ingresar sin mayores dificultades en un complejo orden discursivo que asume la añoranza como perspectiva posible de un sentido que también puede ser-y es- triunfalista. ${ }^{6}$

\footnotetext{
${ }^{4}$ Carpio atribuye el texto a Mariano Lino Urquieta y lo considera uno de los yaravíes populares más tardíos.

${ }^{5}$ En éste y en casos similares los textos citados deben considerarse en calidad de ejemplos y ciertamente no todos los poemas que contienen se relacionan con la migración.

${ }^{6}$ En todo caso sería importante periodizar el flujo migratorio. Al parecer sus diversos momentos generan preferencias por ciertos tonos, aunque no invaliden los otros. Sin proponérselo explícitamente hay esbozos de periodización en Matos, Rodríguez, Golte y Adams, Méndez (véase bibliografia).
} 
De hecho, problematizando la consistencia de la tópica elegiaca, Golte y Adams comprueban con solvencia - desde las ciencias sociales- que pese a todas las penurias imaginables cabe extraer de la experiencia de los migrantes una "historia de logros, de orden y concierto, de pobladores que construyen sus viviendas y sus vidas"; o si se quiere, para ser más enfáticos, una "versión de los vencedores" (1987, 17-18). Esta perspectiva tiene plasmaciones textuales numerosas (Bueno, 1980; Jara, 1989), ${ }^{7}$ pero tal vez ninguna posea la fuerza triunfal que anima la obra mayor de la poesía quechua de José María Arguedas. Cito la traducción al español de un fragmento de su himno "A nuestro Padre Creador Túpac Amaru":

Somos miles de millares, aquí, ahora. Estamos juntos; nos hemos congregado pueblo por pueblo, nombre por nombre, y estamos apretando a esta inmensa ciudad que nos odiaba, que nos despreciaba como a excremento de caballos. Hemos de convertirla en pueblos de hombres que entonen los himnos de las cuatro regiones de nuestro mundo, en ciudad feliz, donde cada hombre trabaje, en inmenso pueblo que no odie y sea limpio como la nieve de los dioses montañas (Arguedas [1962], 1972, 23-24).

La utopía arguediana (simbolizada en la "ciudad feliz") no se cumplió, por supuesto, pero la gran ola migrante logró metas fundamentales y transformó radicalmente el orden de una ciudad que nunca más repetirá - salvo en parodias desintencionadas-su hechiza heráldica virreinal. Es importante evitar, entonces, la perspectiva que hace del migrante un subalterno sin remedio, siempre frustrado, repelido y humillado, inmerso en un mundo hostil que no comprende ni lo comprende, y de su discurso no más que un largo lamento del desarraigo; pero, igualmente, es importante no caer en estereotipos puramente celebratorios: también hay migrantes instalados en el nicho de la pobreza absoluta, desde donde opera la nostalgia sin remedio, la conversión del pasado en utópico paraíso perdido o el deseo de un retorno tal vez imposible, aunque hay que advertir - y esto es decisivo- que incluso el éxito menos discutible no necesariamente inhibe los tonos de la añoranza. En otras palabras: triunfo y nostalgia no son términos contradictorios en el discurso del migrante.

De otro lado, es inexacto imaginar que la migración opera como fuerza imbatible y todopoderosa que reconstruye desde sus raíces la identidad del migrante campesino, convirtiéndolo, por ejemplo, en protagonista de la "larga marcha" — supuestamente casi siempre exitosa - hacia la propiedad privada y el capitalismo (De Soto, 1986), entre otras muchas razones porque el migrante tiende a repetir en la ciudad modos de producción y de relaciones sociales - como la reciprocidad, la operatividad económica de la familia ampliada o el simple padrinazgo- que difícilmente se incorporan a las normas del capitalismo moderno. Los antropólogos antes mencionados constatan que la experiencia de origen, previa al viaje a la ciudad, condiciona fuertemente el modo de inserción urbana del migrante y dota a su aventura personal de una coherencia colectiva (Golte y Adams, 1987, 18, passim). Esto permite sospechar que el migrante tanto está expuesto a fenómenos sincréticos, en relación a las fuerzas que surgen de su nuevo espacio de experiencia, cuanto puede fijar deslindes relativamente claros entre los dos o más momentos de su itinerario. Al parecer, la conciencia

${ }^{7}$ La novela de Jara merecería un análisis más detenido. 
del migrante está más atenta a la fijación de sus experiencias distintas y encontradas que a la formulación de una síntesis globalizadora.

Ciertamente no trato de fijar límites, estableciendo polos entre la nostalgia y el triunfo, o entre la construcción de nuevas identidades o la reafirmación de las antiguas, y menos secuencializar los extremos en una historia más o menos lineal; exactamente al contrario, pretendo construirun espacio donde cualquier sentido puede solaparse y refundirse precisamente en el extremo que aparentemente se le opone, como también -y tal vez sobre todoestratificar como instancias separadas las diversas vivencias que forman su fluido itinerario a través de distintos tiempos y espacios. Repito en este caso mi estrategia de leer no tanto la linealidad de un discurso cuanto su espesor - bajo el supuesto, otras veces aludido (Cornejo, 1994, 18 passim), de que la historia corre pero también se adensa en el tiempo. Después de todo no hay mejor discurso sobre la identidad que el que se enraíza en la incesante(e inevitable) transformación.

Mi hipótesis primaria tiene que ver con el supuesto que el discurso migrante es radicalmente descentrado, en cuanto se construye alrededor de ejes varios y asimétricos, de alguna manera incompatibles y contradictorios de un modo no dialéctico. Acoje no menos de dos experiencias de vida que la migración, contra lo que se supone en el uso de la categoría de mestizaje, y en cierto sentido en el del concepto de transculturación, no intenta sintetizar en un espacio de resolución armónica; imagino - al contrario— que el allá y el aquí, que son también el ayer y el hoy, refuerzan su aptitud enunciativa y pueden tramar narrativas bifrontes $\mathrm{y}$ - hasta si se quiere, exagerando las cosas - esquizofrénicas. Contra ciertas tendencias que quieren ver en la migración la celebración casi apoteósica de la desterritorialización (García Canclini, 1990), ${ }^{8}$ considero que el desplazamiento migratorio duplica (o más) el territorio del sujeto y le ofrece o lo condena a hablar desde más de un lugar. Es un discurso doble o múltiplemente situado.

No está demás añadir que en el mayor estudio psicoanalítico sobre la extrema pobreza en las barriadas de Lima, en cuya demografia priman sustancialmente los migrantes, los reportes y las reflexiones de los terapeutas - leídos desde una perspectiva lega- casi no consignan relaciones comparativas entre el ayer y el hoy del migrante —o sólo de manera incidental y poco significativa-, tal vez porque en las circunstancias que se realizó la investigación (durante la crisis de los años 80) los pobladores migrantes estaban obsedidos por las urgencias de la difícil supervivencia cotidiana. Aunque se refiere a otro asunto la siguiente frase podría sintetizar parcialmente lo anterior:

Pareciera que la señora se siente "en tierra de nadie", ni arriba, ni abajo, que a su vez son imaginados por ella como totalmente desconectados entre sí (Rodríguez, 1989, 61, énfasis mío).

Por supuesto, las experiencias no son nunca tan tajantes, pero insisto en que todo indicaría que el migrante no está especialmente dispuesto a sintetizar las distintas estancias de su itinerario, aunque —como es claro- le sea imposible mantenerlas encapsuladas y sin comunicación entre sí.

\footnotetext{
${ }^{8}$ Obviamente García Canclini matiza este tema con sutileza.
} 
Aunque escapa al marco espacial y temporal de estas reflexiones, no encuentro mejor ejemplo del discurso migrante - por su capacidad de problematización-que un fragmento del capítulo inicial de Los rios profundos - que antes lo he trabajado dentro de otro argumento (Cornejo, 1994, 213-219). Se refiere al momento en que Ernesto llega al Cusco y se enfrenta por vez primera a los viejos muros incaicos. Viéndolos, extasiado, dice:

Me acordé, entonces, de las canciones quechuas que repiten una frase patética constante: "yawar mayu", río de sangre; "yawar unu", agua sangrienta; "puk'tik' yawar k'ocha”, lago de sangre que hierve; "yawar wek'e", lágrimas de sangre. ¿Acaso no podría decirse "yawar rumi", piedra de sangre o " puk'tik' yawar rumi", piedra de sangre hirviente? [...]-iPuk'tik' yawar rumi! - exclamé frente al muro, en voz alta (Arguedas, 1958, 18).

Es claro que el migrante adolescente que opera como narrador-personaje de la novela concentra pero no sintetiza en su discurso dos experiencias, una pasada y otra presente. De hecho actualiza dos idiomas, quechua y español; dos tecnologías comunicativas, la oral y la escrita; dos géneros artísticos, la canción y la novela; y de alguna manera, pero la relación podría continuar, ejercita dos sistemas culturales distintos. El orden de este extendido dualismo parece ser una suerte de metonimia que extrae de una primera (agua-sangre) el modelo que permite la segunda (agua-piedra) - que ciertamente implica un desplazamiento harto más complejo en cuya dinámica probablemente se ejerzan ciertas dimensiones del pensamiento mítico. Desde esta perspectiva, el texto se desdobla continuamente y en su resolución se plasma una figura ambigua - la de la "piedra de sangre hirviente"- que no necesariamente supone una síntesis, aunque (como es obvio) ésta también sería una lectura factible. En cualquier caso lo que me interesa poner de relieve es la actuación de un sujeto que maneja una pluralidad de códigos que pese a ingresar en un solo rumbo discursivo no sólo no se confunden sino que preservan en buena parte su propia autonomía. El narrador-personaje habla sin duda desde dos espacios.

Pero si el texto de Arguedas actualiza en un solo enunciado posiciones muy diversas, hay otros donde la fragmentación del sujeto adquiere características harto más dramáticas. Me refiero a los textos recogidos por Zapata y Biondi, en especial el que aparece en labios del "cómico ambulante". ${ }^{9}$ Los mencionados autores a más de transcribir los discursos de los "oradores populares" que ahora ocupan los principales espacios públicos de Lima, analizan con notable sagacidad las estrategias discursivas de estos nuevos productores de significados ampliamente socializados y concluyen proponiendo - claro que con una riqueza conceptual que mi resumen inevitablemente tergiversa- que la ciudad ha sido re-ocupada por la oralidad (1994, 9-34).

No me es posible dar razón del discurso íntegro del "cómico ambulante", que por lo demás se desliza entre varios temas y se interrumpe con diálogos con el público, todo en un lenguaje grueso que usa sin reparos, una y otra vez, significados e imágenes coprolálicos, pero sí me interesa remarcar lo que podría denominarse las intensas fluctuaciones de su identidad discursiva. En efecto, primero emplea una filiación englobante, como perteneciente al pueblo,

\footnotetext{
${ }^{9}$ Un texto muy similar, aunque transcrito mediante otra técnica, se encuentra en Habla la ciudad (véase bibliografia). En este caso se anota que el cómico realiza su actuación vestido de mujer. El dato podría añadirse a las oscilaciones de la identidad del sujeto.
} 
luego se define más específicamente como "nosotros los criollos", en contraposición a "los provincianos" (con lo que él se identifica como limeño) y más específicamente a "la gente de la sierra", a la que agresivamente califica de "estos mierdas" (444), para — pocos minutos después, luego de elogiar a los fundadores del imperio incaico y a Túpac Amaru-definirse él mismo como provinciano y serrano: "si tú eres provinciano nunca niegues a tu tierra. Yo vivo orgulloso como serrano que soy, serrano a mucha honra, serranazo" (448).

¿Cómo explicar estas oscilaciones en la identidad del emisor? Por supuesto, no hay que olvidar que se trata mucho más de una performance que de un texto y que esa condición aligera notoriamente los requerimientos de la coherencia propia de la escritura, en especial de la literatura canonizada; como tampoco se puede pasar por alto que el orador callejero necesita crear espacios intersubjetivos, o de pertenencia compartida, con un público que pagará o no por su rendimiento profesional -tema que obsesiona al cómico. Creo, sin embargo, que hay mucho más: él dramatiza en y con su lenguaje la condición migrante y habla con espontaneidad desde varios lugares, que son los espacios de sus distintas experiencias, autorizando cada segmento del discurso en un locus diverso, con todo lo que ello significa, incluyendo la transformación de la identidad del sujeto, locus que le confiere un sentido de pertenencia y legitimidad y que le permite actuar como emisor fragmentado de un discurso disperso. Lo notable del asunto es que el abrupto descentramiento del discurso no parece producir ninguna tensión en el emisor (y tampoco en los receptores) y su acto de habla se desliza sin contratiempos con una muy curiosa espontaneidad, incluso cuando alguna de las figuraciones del sujeto emite juicios negativos sobre otro sujeto que luego será quien asuma la función enunciativa. Casi se podría pensar, por encima del hecho de que se trata de una sola persona, en la actuación de varios hablantes - lo que obviamente invitaría a un largo regodeo bajtiniano. ${ }^{10}$

Biondi y Zapata consideran con razón que el discurso del cómico se articula mediante el uso intensivo de la metonimia y acopian ejemplos contundentes al respecto (Biondi y Zapata 1994, 336-441), suponiendo - lo que sí es discutible-que la construcción metonímica es propia de la oralidad. No repetiré el meticuloso examen de estos autores, pero si sería oportuno reflexionar sobre si la dinámica de la metonimia, cuyas ondas se expanden bajo la laxitud de la norma de la contigüidad, tanto asociativa como opositiva, no favorece este tipo de discursos descentrados, que se desparraman en un espacio casi ilimitado y que —en cierta forma al menos - repite el azaroso itinerario del migrante. ${ }^{11}$ De hecho, al contrario de la metáfora, que se cierra en la similaridad de sus componentes, además poco numerosos, la metonimia carece de centro y puede ampliarse con notable libertad. Naturalmente habría que profundizar en el tema, pero no deja de ser atractivo relacionar las variadas figuraciones y discursos del sujeto migrante, y sus diversas estrategias representativas, con este ir y venir de la metonimia: tal vez en la deriva del curso metonímico el migrante encuentre lugares desiguales desde los que sabe que puede hablar porque son los lugares de sus experiencias. Serían las voces múltiples de las muchas memorias que se niegan al olvido.

\footnotetext{
${ }^{10}$ Me refiero sobre todo, como es claro, al concepto de dialogismo y similares. Creo que no tendría sentido confirmar ahora la pertinencia de las ideas de Bajtín, y sospecho que el caso en análisis puede exceder sus marcos teóricos.

"Aunque no los empleo en este caso, siguen siendo indispensables los aportes de Jakobson. No dejan de tener interés, aunque demasiado casuísticos, los de Le Guern (véase bibliografia).
} 


\section{BiBLIOGRAFÍA}

Arguedas, José María. Amor mundo y todos los cuentos. Lima: Moncloa, 1977.

Arguedas, José María. Los rios profundos. Buenos Aires: Losada, 1958.

Arguedas, José María. Temblar/Katatay. Lima: Instituto Nacional de Cultura, 1972.

Biondi, Juan y Eduardo Zapata. Representación oral en las calles de Lima. Lima: Universidad de Lima, 1994.

Bueno, Leoncio. La guerra de los Runas. Lima: Túngar, 1980.

De Soto, Hernando. El otro sendero. La revolución informal. Lima: Barranco, 1986.

Carpio Muñoz, Juan Guillermo. El yaraví arequipeño. Un estudio histórico-social y un cancionero. Arequipa: La Colmena, 1986.

Consejo Nacional de Población (CONAPO). Perú: hechos y cifras. 1988. Lima: Dirección General de Estudios en Población, 1989.

Espino, Gonzalo. Casa Hacienda. Lima: Lluvia, 1990.

García Canclini, Néstor. Culturas hibridas. Estrategias para entrar y salir de la modernidad. México: Grijalbo, 1990.

Golte, Jürgen y Norma Adams. Los caballos de Troya de los invasores. Estrategias campesinas en la conquista de la gran Lima. Lima: IEP, 1987.

Jakobson, Roman. "Dos aspectos del lenguaje y dos tipos de trastornos afásicos". Jakobson, Roman y Morris Halle. Fundamentos del lenguaje. Madrid: Ciencia Nueva, 1967.

Jara, Cronwell. Patíbulo para un caballo. Lima: Mosca Azul, 1989.

Lauer, Mirko. El sitio de la literatura peruana. Escritores y política en el Perú del siglo XX. Lima: Mosca Azul, 1989.

Le Guern, Michel. La metáfora y la metonimia. Madrid: Cátedra, 1985.

Matos Mar, José. Las barriadas en Lima. 1957. Lima: Instituto de Estudios Peruanos, 1977 ( $2^{\mathrm{a}}$ ed. revisada y aumentada).

Montoya, Rodrigo, Edwin y Luis. La sangre de los cerros/Urqukunapa yawarnin. Lima: Mosca Azul, Universidad de San Marcos, CEPES, 1987.

Méndez Gastelumendi, María. Los jóvenes del nuevo Perú profundo. Lima: DESCO, 1990.

Nelson, Julio. Caminos de la montaña. Lima: La escena contemporánea, 1982.

Quijano, Aníbal. Dependencia, urbanización y cambio social en América Latina. Lima: Mosca Azul, 1977.

Quijano, Aníbal. Dominación y cultura. Lo cholo y el conflicto cultural en el Perú. Lima: Mosca Azul, 1980.

Rama, Ángel. La ciudad letrada. Hanover: Norte, 1984.

Rodríguez Rabanal, César. Cicatrices de la pobreza. Un estudio psicoanalítico. Caracas: Nueva Sociedad, 1989.

Vallejo, César. Obra poética completa. Lima: Moncloa, 1968.

Vargas Llosa, Mario. La tia Julia y el escribidor. Barcelona: Seix Barral, 1977.

Varios. Habla la ciudad. Lima: Universidad de San Marcos y Municipalidad de Lima, 1986. 